\title{
Radiation Effects in the Cloud-topped Marine Boundary Layer
}

\author{
HuNG-CHI KUO* \\ Naval Oceanographic and Atmospheric Research Laboratory \\ Monterey CA. 93943-5006, U.S.A.
}

(Received 10 April 1990; revised 15 May 1990)

\begin{abstract}
This paper investigates the interaction between dynamics and infrared radiation in the cloud-topped marine boundary layer. A two: dimensional Boussinesq moist model with a numerical technique (Fourier-Chebyshev spectral tau method) and resolution $(10 \mathrm{~m})$ sufficient to simulate cloud top processes has been used. With the spectral tau method and the fourth-order Runge-Kutta time integration scheme, great computational efficiency are realized even with high model accuracy.

Measurements suggest that the cloud-top radiative cooling is likely to exhibitsignificant horizontal as well as vertical variability which is principally governed by the variability of cloud liquid water. To investigate the impact of infrared cooling on boundary layer dynamics, numerical experiments on marine boundary layer convection under various idealized radiative forcings are performed. The results indicate that the dynamics of the cloud-topped marine boundary layer do not depend on the horizontal and the vertical distribution of the cooling so long as the cooling is confined to the turbulent boundary layer. The sensitivity of stratocumulus-topped boundary layer dynamics to the infrared cooling appears to be primarily in the vertical placement of the cooling relative to the turbulent cloud top region. This is due to the fact that the turbulent dynamical mixing time scale is smaller than the radiation build up time scale. Before radiation can cool a local region appreciably to influence the dynamics, the circulation inside the boundary layer has already transported the cloudy parcel out of the radiative cooling zone. Since the theory of radiation does not support the existence of infrared cooling in the capping inversion (zero cloud fraction or non-turbulent region), the spatial variability of cloud-top cooling needs to be considered only when the radiation build up time scale is comparable to the turbulent mixing time scale.
\end{abstract}

* Present affiliation: Department of Atmospheric Sciences, National Taiwan University, Taipei, Taiwan, R.O.C. 


\section{INTRODUCTION}

In his pioneering work on the cloud-topped marine boundary layer, Lilly (1968) disregarded the effects of the surface shear-generated turbulence but considered radiation from the cloud tops as an essential element in the maintenance of a mixed layer 500 to $1000 \mathrm{~m}$ or more in thickness. He argued that "It would appear impossible for any observed combination of subsidence, convection, and shear turbulence to produce sufficient amounts of kinetic energy to maintain a 15-20 degree inversion at a height of $500-1000 \mathrm{~m}$ without a radiatively effective cloud cover." Since the publication of Lilly's paper, this importance of cloud top infrared radiation loss has been generally accepted. Numerous theoretical as well as observational studies have concentrated not only on the longwave but also on the shortwave radiative properties of marine stratocumulus clouds.

Estimates of cloud shortwave absorption vary considerably and both Reynolds et al. (1975) and Stephens et al. (1978) report large values of absorption of solar radiation. Aircraft observations in the Joint Air-Sea Interaction experiment (JASIN) indicate that at midday the shortwave heating approximately cancels the longwave cooling of the cloud. Thus, a diurnal cycle of the stratocumulus layer is expected according to these measurements (Slingo et al. 1982a). However, great discrepancies exist between the observations and theoretical calculations of solar absorption in stratocumulus. The observations indicate the solar absorption can be as large as $20 \%$ while the theoretical calculations suggest only $6 \%$ (Wiscombe et al. 1984). Several mechanisms have been proposed to reconcile the differences between theory and measurement. Grassl (1975) showed that the presence of aerosols in clouds can produce increased absorption. Since many of the measurements showing anomalous absorption were taken in clouds far from known pollution sources, the question remains as to whether there would be sufficient aerosol present to significantly influence cloud absorption. Welch et al. (1980) and Wiscombe et al. (1984) performed calculations which suggest that excess absorption of solar radiation may be due to precipitation or very large droplets in the clouds. Twomey (1978) pointed out that departures of the cloud from stratiform geometry may invalidate the derivation of the absorption from the observed fluxes, because some radiation would be lost through the sides of the cloud. This particular issue of the large observed solar absorption in clouds (Absorption Paradox) is still an open question. Therefore, only the interaction between dynamics and infrared radiation will be considered in this paper.

The studies of the cloud top infrared radiation in nocturnal stratocumulus indicate a good agreement between the measured longwave fluxes and cooling rates and theoretical calculations (e.g., Stephens et al., 1978; Slingo et al., 1982b; Kuo, 1983; Fouquart 1985). The typical cloud top cooling is about 3-10 

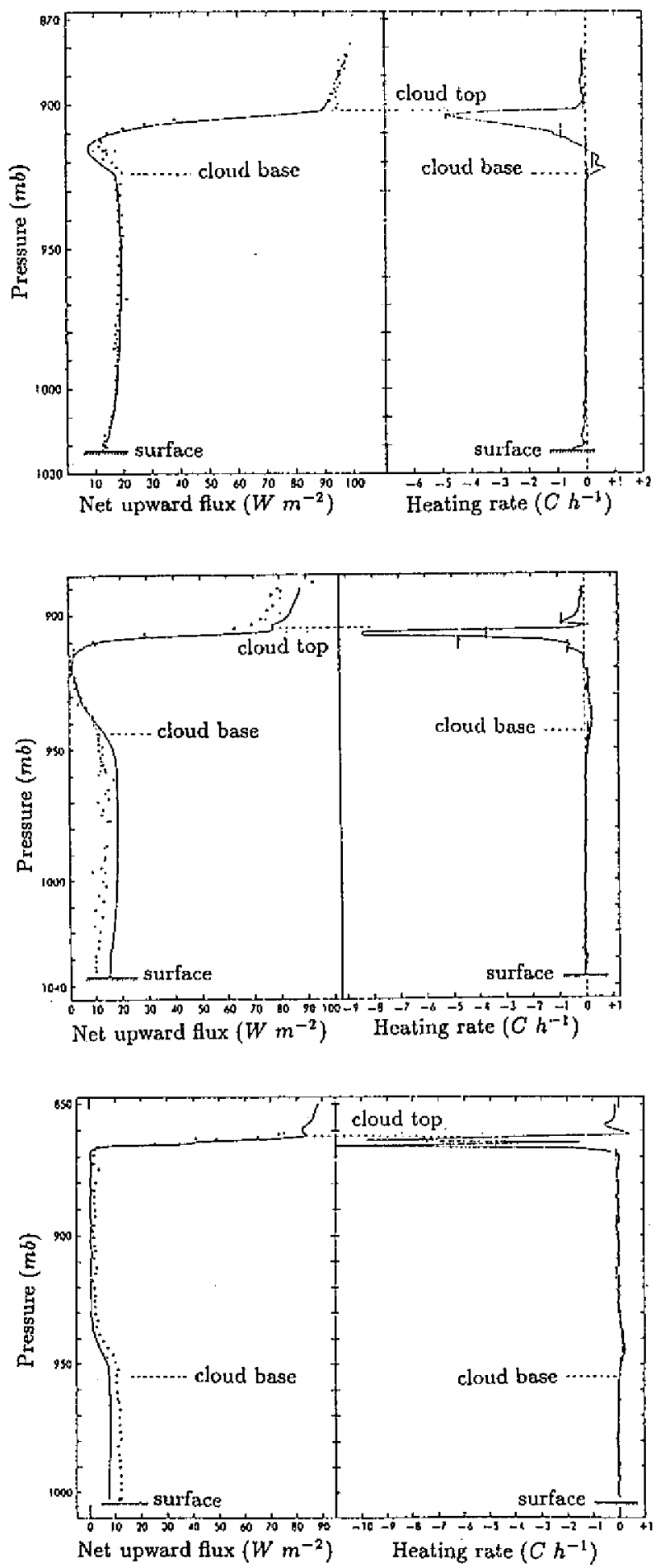

Fig. 1. Comparsion of the observed (dotted lines) and theoretical (solid lines) net infrared fluxes and cooling rates. The three measurements are arranged in order of increasing cloud thickness. (from Slingo et al., 1982b). 
$K h^{-1}$ and covers the top 50-100 $\mathrm{m}$ of the cloud. In addition, the effective emissivity of the cloud can be accurately parameterized by the liquid water path (Stephens et al., 1978; Slingo et al., 1982b). Tethered balloon observations have been used by Slingo et al. (1982b) to study cloud microphysics and infrared radiation effects in a layer of nocturnal stratocumulus. Although these observations were taken over land (Cardington, England), they have many characteristics in common with marine stratocumulus. The three panels of Fig. 1 (from Slingo et al., 1982b) show the vertical profiles of the net upward infrared flux and the cooling rate taken from the tethered balloon observations on three separate nights. These pictures are arranged in order of increasing cloud thickness. We observe from Fig. 1 that as the clouds become thicker the infrared cooling becomes more confined to the cloud top. Moreover, the magnitude of the cooling varies as the cloud thickness varies. Thus, the infrared radiative forcing in the marine boundary layer is very sensitive to the cloud liquid water content. Aircraft measurements in stratocumulus clouds off the east coast of Australia such as reported by Stephens and Platt (1987) indicate the horizontal inhomogeneity of stratocumulus clouds. The fractional deviation of cloud liquid water content as a function of the normalized in-cloud depth for three of the flights are plotted in Fig. 2. The fractional deviation here is defined as the ratio of the standard deviation divided by its mean and all the horizontal flight paths are $16 \mathrm{~km}$ long. Note that the fractional deviation of the cloud liquid water is large throughout the whole cloud layer. The results in Fig. 2 suggest that cloud liquid water is highly variable along a given level inside the cloud.

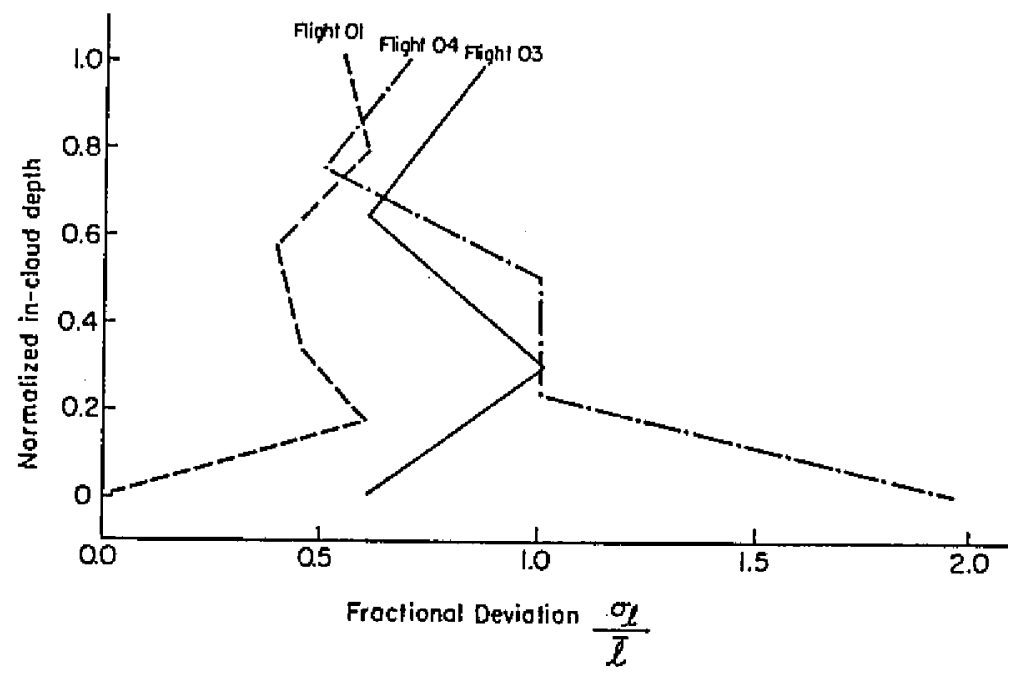

Fig. 2. The fractional deviation of cloud liquid water as a function of the normalized in-cloud depth. The fractional deviation is defined as the ratio of the standard deviation divided by its mean. The horizontal flight paths are $16 \mathrm{~km}$ long. (adopted from Stephens and Platt, 1987).

The observations presented in Figs. 1 and 2 highlight the significant hor- 
izontal as well as vertical variability of the cloud top radiative cooling. Since the infrared radiation is the driving force of the boundary layer, one might then wonder how the boundary layer dynamics will vary according to these different spatial distributions of radiative cooling. In addition, because the horizontal variability of the optical medium (stratocumulus) is as extreme as the vertical variability, the usefulness of the classical one-dimensional plane parallel radiative transfer calculation in a fine resolution dynamical model is questionable. On the other hand, the need to take the horizontal variability of radiation fields into account will depend on how the boundary layer dynamics are affected by the various spatial distributions of radiative cooling. The purpose of this paper is to understand how the dynamics in the cloud-topped marine boundary layer are affected by vertical and horizontal variations of infrared radiative forcings. In section 2, descriptions of the dynamical model and the idealized infrared forcings are presented. Numerical experiments based on the various infrared forcings are discussed in section 3 . In section 4 we perform a mixing line analysis on the model results which demonstrates the difference between the dynamical mixing time scale and the radiation build up time scale. Section 5 contains the concluding remarks and summary.

\section{MODEL DESCRIPTIONS AND INFRARED RADIATIVE FORCINGS}

The numerical model described in Kuo and Schubert (1988), Kuo (1987) and Kuo and Vonder Haar (1986) is employed in the current study. The model is based on Ogura and Phillip's (1962) Boussinesq equations for shallow moist convection. Prognostic variables in the model are equivalent potential temperature $\theta_{e}$, vorticity and total water mixing ratio $r$. Iteration is required during time integration to diagnose potential temperature $\theta$, liquid water mixing ratio $l$ and water vapor mixing ratio $q$ from $\theta_{e}$ and $r$. The refined Newton scheme is used in the moisture physics iteration. With the refined Newton scheme, it takes three iterations to produce the machine accuracy solutions of $\theta, q$ and $l$. In all the simulations the model domain is $2500 \mathrm{~m}$ in the (periodic) horizontal direction and $800 \mathrm{~m}$ in the vertical. The spectral discretization is Fourier-Galerkin in the horizontal and Chebyshev-tau in the vertical, with 64 modes in each direction $(N=M=64)$. The transform method (Orszag, 1970; Eliasen et al., 1970) is used in computing the spectral coefficients of nonlinear and diabatic terms. To eliminate aliasing error, transform grids consist of 192 equally spaced points in the horizontal and 96 unequally spaced points (collocation points) in the vertical are used in physical space, giving an approximate resolution of nearly $10 \mathrm{~m}$ in each direction. A four second time step is used in the fourth-order Runge-Kutta time integration. This four second time step retains the full accuracy of the spatial discretization. With the Fourier-Chebyshev spectral spatial 
discretization and the fourth-order Runge-Kutta time integration scheme, we achieve high accuracy with far fewer degrees of freedom, the method is computationally efficient even when high accuracy is desired (Fulton and Schubert, 1987; Kuo, 1987; Schubert et al., 1984). The second-order diffusion process is used in the $x$ direction and a more scale-selective fourth-order diffusion is used in the $z$ direction. The coefficient of eddy diffusivity $k_{x}$ is $1.8 \mathrm{~m}^{2} \mathrm{~s}^{-1}$ and $k_{z}$ is $8 \mathrm{~m}^{4} \mathrm{~s}^{-1}$ in the present study. These coefficients have been chosen so that the cascade in the model will not lead to spectral blocking. In testing the model we found that the time and horizontally averaged fluxes from a radiatively forced model change little when $k_{x}$ and $k_{z}$ are changed by a factor of two. A large scale subsidence is specified according to a climatological divergence value of $5 \times 10^{-6} \mathrm{~s}^{-1}$. Additional upper inflow boundary conditions for $\theta_{e}$ and $r$ are also specified. The ocean is assumed to have a surface potential temperature $\theta_{s f c}$ of $286.2 \mathrm{~K}$. This sea surface temperature corresponds to a saturation mixing ratio $q_{s f c}^{*}$ of $9.4 \mathrm{~g} \mathrm{~kg}^{-1}$ and a $\theta_{e s f c}$ of $309.3 \mathrm{~K}$. The surface fluxes are computed by the bulk formulas, i.e.

$$
\begin{aligned}
& {\overline{w^{\prime} \theta_{e s f c}^{\prime}}}=C_{T} V\left(\theta_{e s f c}-\theta_{e r e f}\right), \\
& {\overline{w^{\prime} r^{\prime}}}_{s f c}=C_{T} V\left(q_{s f c}^{*}-r_{r e f}\right),
\end{aligned}
$$

where $\theta_{\text {eref }}$ and $r_{\text {ref }}$ are the equivalent potential temperature and total water at a reference level (i.e. at the top of the surface layer, $25 \mathrm{~m}$ ) and $C_{T}$ is the bulk transfer coefficient, which has the constant value of 0.0015 . The surface wind speed $V$ is taken to be $7 \mathrm{~m} \mathrm{~s}^{-1}$ in the present study. The $\theta_{e}$ and $r$ fluxes in the surface layer have a specified height dependence which decreases to nearly zero at the top of the surface layer.

The initial conditions considered here consist of a well mixed but motionless boundary layer with a depth of about $450 \mathrm{~m}$. The vertical profiles of equivalent potential temperature $\theta_{e}$, potential temperature $\theta$, cloud liquid water $l$ and water vapor $q$ for the initial sounding is shown in Fig. 3. Note that the cloud top jump conditions in this initial sounding is the same as one of the Oakland soundings presented by Lilly (1968). The equivalent potential temperature in this mixed layer is $305.0 \mathrm{~K}$ and total water mixing ratio is $7.9 \mathrm{~g} \mathrm{~kg}^{-1}$. The sub-cloud potential temperature is very near the sea surface temperature. The inversion depth is $100 \mathrm{~m}$. The cloud layer in this boundary layer extends from $200 \mathrm{~m}$ to $450 \mathrm{~m}$ with the liquid water content increasing nearly linearly with height at the adiabatic rate. The peak liquid water content in the cloud is 0.38 $g \mathrm{~kg}^{-1}$. The inversion air above the boundary layer has a total water content of $2 \mathrm{~g} \mathrm{~kg}^{-1}$ and a $\theta_{e}$ of $311 \mathrm{~K}$. In addition, $\theta_{e}$ gradually increases at a rate of $0.01 \mathrm{~K} \mathrm{~m}^{-1}$ from the inversion top to the model top. 

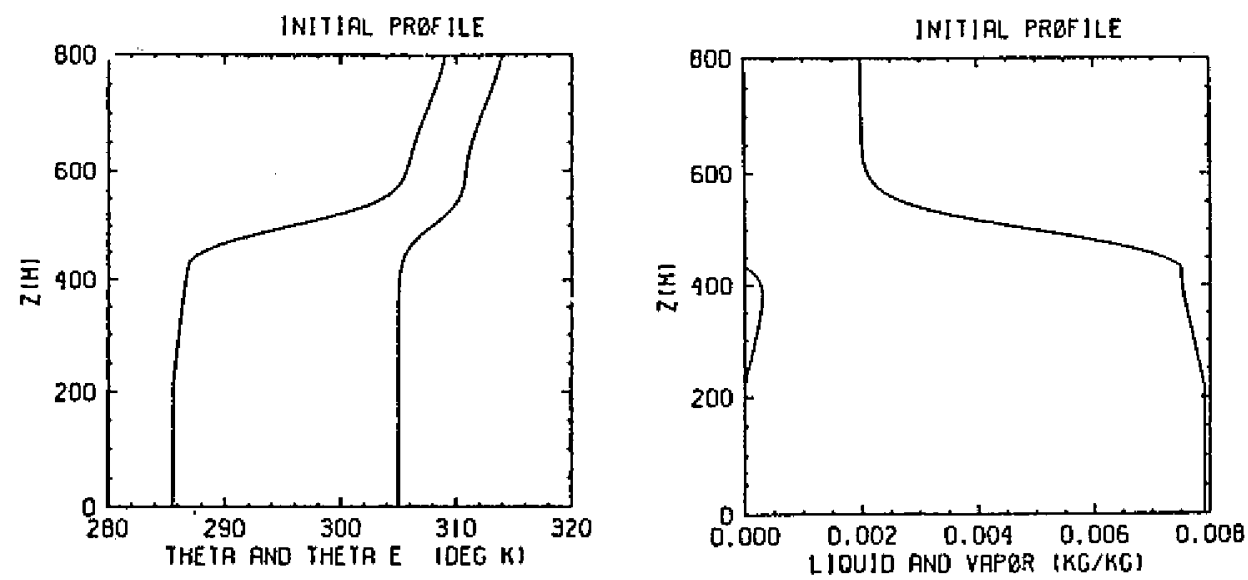

Fig. 3. The initial profiles of $\theta_{e}$ the equivalent potential temperature, $\theta$ the potential temperature, $q$ the mixing ratio of water vapor and $l$ the mixing ratio of liquid water used in the numerical experiments.

To understand the impact of the various infrared cooling profiles on boundary layer dynamics, the initial sounding illustrated above will be time integrated under several simple but different radiative forcings. Because of the low cloud base and cold ocean surface temperature (about the same as the surface air temperature), cloud base warming by infrared radiation can be neglected. The idealized cloud top infrared radiative cooling will be handled either non-interactively or interactively. Five profiles of infrared radiative forcing are presented in Fig. 4. The cooling profiles $\mathrm{C}, \mathrm{D}$ and $\mathrm{E}$ are for the non-interactive radiative forcings while profiles $A$ and $B$ are for the interactive forcings. The vertical bar in Fig. 4 indicates the vertical extent of the initial cloud. The non-interactive radiative forcings are horizonally homogeneous and steady state. The cooling in profiles $\mathrm{D}$ and $\mathrm{E}$ is $50 \mathrm{~m}$ deep and has a peak of about $-11 \mathrm{~K} \mathrm{hr}^{-1}$. The cooling profile $\mathrm{C}$ covers a depth of $120 \mathrm{~m}$ and peaks at $350 \mathrm{~m}$ with a magnitude of about $3.5 \mathrm{~K} \mathrm{hr}^{-1}$. The cooling region in profile $\mathrm{E}$ is well into the capping inversion, in profile $\mathrm{C}$ it is deep inside the cloud and in profile $\mathrm{D}$ it is near the cloud top. Throughout most of the model integration, forcing $\mathrm{C}$ is in the one hundred percent cloud fraction region while forcing $\mathrm{E}$ is in the clear region. The cloud fraction in the region where the cooling $D$ is placed may become less than one hundred percent during the integration due to the formation of small gaps between cloud cells. Parts of the cooling will unavoidably be applied to clear regions between cloud cells. We will use these non-interactive forcings to study the importance of different vertical distributions of radiative cooling.

The interactive infrared radiative forcings (forcings $A$ and $B$ ) are designed to produce cooling distributions which resemble the plane parallel radiative transfer results in the dynamical model. The forcings A and B will then follow the horizontal variation of cloud liquid water field and are confined to the top 
$75 \mathrm{~m}$ of the cloud. The height of the maximum cooling in the interactive forcings as a result varies to follow the cloud top topography. The radiative forcing $A$ occurs in a $75 \mathrm{~m}$ deep layer with the peak cooling in the center of the layer. The maximum cooling rate in forcing $\mathrm{A}$ is about $3.5 \mathrm{~K} \mathrm{hr}^{-1}$ which is very close to the peak value in forcing $C$. The profile $B$ is similar to profile $A$ except the maximum cooling is at the very top of the layer where cooling is applied. From cooling profile $\mathrm{A}$ or $\mathrm{B}$ as well as the initial cloud liquid water content profile in the top $75 \mathrm{~m}$ of the cloud, we can find a height dependent ratio of infrared radiative cooling rate divided by liquid water content. To find the magnitude of the cooling at one vertical column during the time integration, the local cloud top height has to be found first. The cooling rate is then determined by multiplying the cloud liquid water content by the corresponding ratio counting from the cloud top down. Thus, the cooling will always cover about the top $75 \mathrm{~m}$ of the cloud in each vertical column with its magnitude depending on the amount of the liquid water content locally. The vertical distribution of the cooling depends on whether profile A or B is used in computing the height dependent ratio. This radiative forcing is interactive in the sense that the amount of cooling occurring locally is linearly proportional to the amount of liquid water diagnosed from the model. There will be no radiative cooling locally if cloud holes are formed; all the cooling is confined to the cloudy air. The interactive radiation is inhomogeneous in both space and time. The model sensitivity test based on forcings $\mathrm{A}, \mathrm{B}$ and $\mathrm{C}$ will reveal the importance of spatial variability in cloud top cooling.

\section{NUMERICAL EXPERIMENTS}

Satellite pictures reveal that stratocumulus over the cold ocean can exist for several days with little change in appearance. This implies that the boundary layer is often in a steady state. The equilibrium state of the marine boundary layer will be investigated by time and horizontally averaged flux profiles. The fluxes in all the experiments are computed in a one hour period after 60 minutes or 100 minutes of model integration from the initial motionless boundary layer. The 60 minutes or 100 minutes model adjustment time before computation of the flux allows the boundary layer to reach an equilibrium state with fixed external conditions (e.g., the sea surface temperature, subsidence and radiative cooling).

To study the impact of various infrared cooling forcings on boundary layer dynamics, the initial sounding is time integrated under radiative forcings $A$, $\mathrm{B}, \mathrm{C}, \mathrm{D}$ and $\mathrm{E}$ (hereafter referred to as experiments $\mathrm{A}, \mathrm{B}, \mathrm{C}, \mathrm{D}$ and $\mathrm{E}$ ). The mean profiles of all experiments are similar. Thus, only the initial $\theta_{e}$ profile and horizontally averaged $\theta_{e}$ fields from experiments $\mathrm{D}$ and $\mathrm{E}$ are shown in 


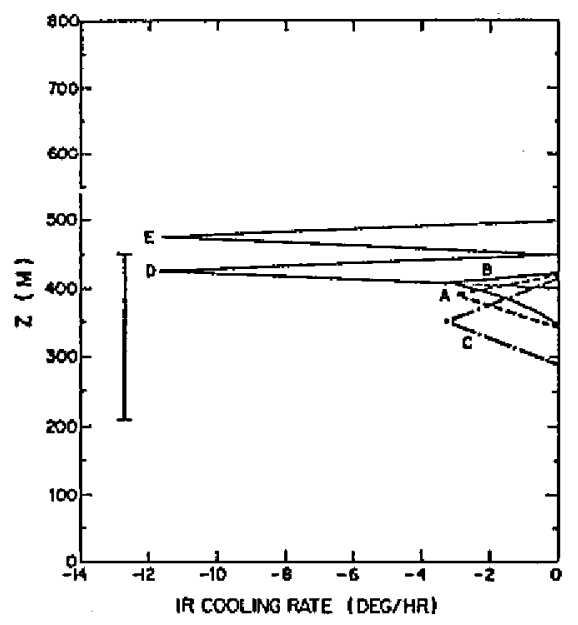

Fig. 4. Five different profiles of infrared radiation cooling forcings used in the numerical experiments. The vertical bar indicates the vertical extent of initial cloud.

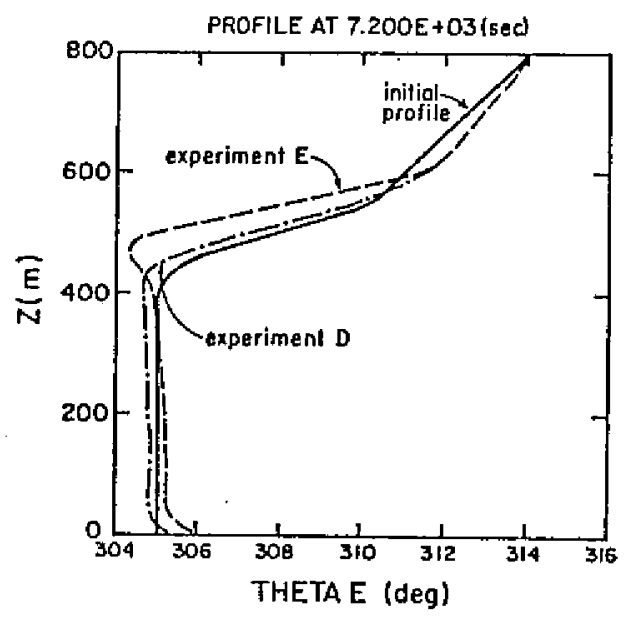

Fig. 5. The vertical profiles of the horizontally averaged $\theta_{e}$ temperature for experiments $\mathbf{D}$ and $\mathbf{E}$ (dash dotted and dash lines) at the end of the model integration time. Also plotted is the initial $\theta_{e}$ profile (solid line) of these two experiments.

Fig. 5. Fig. 5 indicates well mixed layers similar to the initial condition. The local minimum $\theta_{e}$ in the capping inversion from experiment $\mathrm{E}$ is due to the radiative cooling and the lack of dynamical mixing to smooth it. The weak warming above $600 \mathrm{~m}$ in Fig. 5 is due to the effect of subsidence. Fig. 6 shows the infrared cooling distributions in physical space for the experiment $\mathrm{A}$ at 60 minutes and 80 minutes. Also shown are the cloud liquid water mixing ratios in physical space for the same time. The horizontal inhomogeneity as well as the temporal change in the infrared forcing in experiment $A$ as opposed to the horizontally fixed infrared forcings $\mathrm{C}, \mathrm{D}$ and $\mathrm{E}$ is clearly illustrated. Fig. 7 presents the fluxes of $\theta_{e}, \theta, \theta_{v}, r, q$ and $l$ for all the experiments. These flux profiles represent the quasi-steady state of boundary layer dynamics. They are in the energy unit $W \mathrm{~m} \mathrm{~kg}^{-1}$ which is the same as $W \mathrm{~m}^{-2}$ if the air density is taken to be $1 \mathrm{~kg} \mathrm{~m}^{-3}$. There are negative values in the cloud top regions for the buoyancy flux $\left(\theta_{v}\right.$ flux), the heat flux ( $\theta$ flux) and the $\theta_{e}$ flux. These negative regions reflect the phenomena of permanent entrainment. The $\theta_{e}$ flux profiles from all five experiments are similar and comparable to the mixed layer model results of Schubert $(1976,1979)$ and the large eddy simulation of Moeng (1986). The latent heat release inside the cloud contributes to larger $\theta$ and $\theta_{v}$ flux values in the cloud region. The sub-cloud buoyancy and heat fluxes are positive in experiments $\mathrm{A}, \mathrm{B}, \mathrm{C}$ and $\mathrm{D}$ as opposed to the negative values obtained in the classical mixed layer model. The total water and liquid water flux profiles are also comparable to the mixed layer results except for the increase of the flux near 
the cloud top. One point to make here about Fig. 7 is that the individual flux profiles are almost identical for experiments $\mathrm{A}, \mathrm{B}$ and $\mathrm{C}$. The radiative forcings in experiments $\mathrm{A}$ and $\mathrm{B}$ are interactive and horizontally inhomogeneous, and the vertical distribution of cooling involved in experiments $\mathrm{A}$ and $\mathrm{B}$ are different. Experiment $\mathrm{C}$ has a homogeneous cooling deep inside the cloud. These three simple and independent types of cooling produce nearly the same convective flux profiles, indicating that the steady state of the model is insensitive to the vertical as well as the horizontal distribution of the radiative cooling so long as the cooling is inside the cloud. Experiment D generally has similar flux profiles compared to experiments A, B and C. The heat and buoyancy flux profiles in experiment $\mathrm{E}$ are quite different from the rest of the experiments, with small negative heat and buoyancy fluxes near the cloud base region. The sub-cloud heat and buoyancy fluxes in experiment $E$ are smaller than in experiment $D$ even though they both have the same amount of radiative cooling. The flux profiles from Fig. 7 indicate two types of equilibrium state, with experiment $\mathrm{E}$ differing from experiments $\mathrm{A}, \mathrm{B}, \mathrm{C}$ and $\mathrm{D}$.

The velocity field (in arrows) and the cloud liquid water content at the end of the model integration for experiments A, B, C, D and E are shown in Fig. 8. The motion field and liquid water content pictures are shown adjacent to each other. From these liquid water pictures, we see that the simulated clouds are similar in all experiments. The simulated stratocumulus cloud cell resembles a dome with sharp liquid water gradients on the sides. This sharp liquid water gradient has a length scale of approximately $40 \mathrm{~m}$ and sometimes extends down to the cloud base. The regions of the peak liquid water content (e.g., greater than 0.4 $g \mathrm{~kg}^{-1}$ ) appear to be dome shaped and cover the top $50 \mathrm{~m}$ to $100 \mathrm{~m}$ of the cloud cell. The simulated dome-shaped cells and the sharp liquid water gradients near the cloud boundary are conșistent with the fine resolution simulation of cumulus clouds in the absence of ambient shear by Klaassen and Clark (1985). From the velocity pictures, we observed that upward motion is in the center of the stratocumulus cell while downward motion occurs parallel to the cell boundary. As a result, there are deformation fields near the cloud boundary. The sharp liquid water gradients near the cloud boundary are caused by these deformation fields. The downdraft regions do not necessarily have a higher cloud base as predicted by the mixed layer model. This suggests that the downdraft may not always undergo much mixing with the dry inversion air. The updrafts and downdrafts form internal circulations which continually recycle air through the boundary layer and make the boundary layer well-mixed. It should be noted that these simulated circulations are purely buoyancy (radiation) driven because there is no initial background wind shear in the model. In experiments A, B, C and D (Figs. 8a through 8d) there is only one cell of circulation in the vertical as revealed in the velocity field pictures, while there are two circulation cells in 

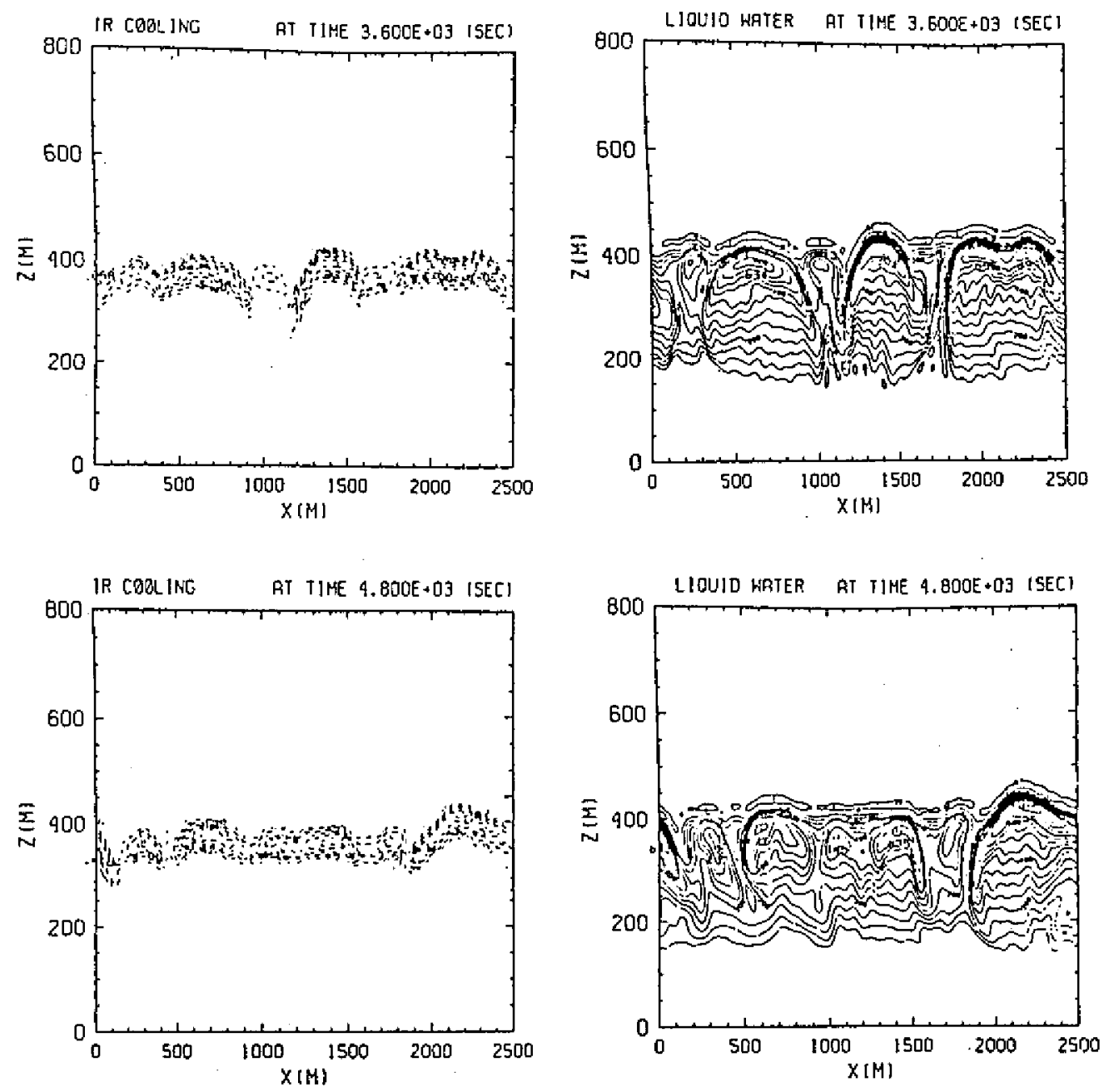

Fig. 6. The infrared cooling (left) and the liquid water mixing ratio field (right) in the physical domain for experiment $A$ at 60 and 80 minutes. The liquid water mixing ratio lines are labeled in $g k g^{-1}$ multiplied by 1000 . The infrared cooling lines are labeled in $K h r^{-1}$.

the vertical in experiment $\mathrm{E}$. The two cell pattern in experiment $\mathrm{E}$ is consistent with its buoyancy flux profile. These two cells of circulation probably are not decoupled in the vertical because the average $\theta_{e}$ profile for experiment $\mathrm{E}$ (Fig. 5 ) is still well-mixed. Also one would expect that the larger in-cloud buoyancy or heat flux should allow the motion to overcome the small negative flux region near the cloud base to reach the moist ocean surface. Finally, as observed in both Figs. 4 and $8 \mathrm{~d}$, the cloud fraction in the region of the prescribed cooling in experiment $\mathrm{D}$ is not one hundred percent because of the formation of domeshaped cloud cells. Some of the non-interactive cooling in experiment D will then inevitably be applied to clear regions between cloud domes. 

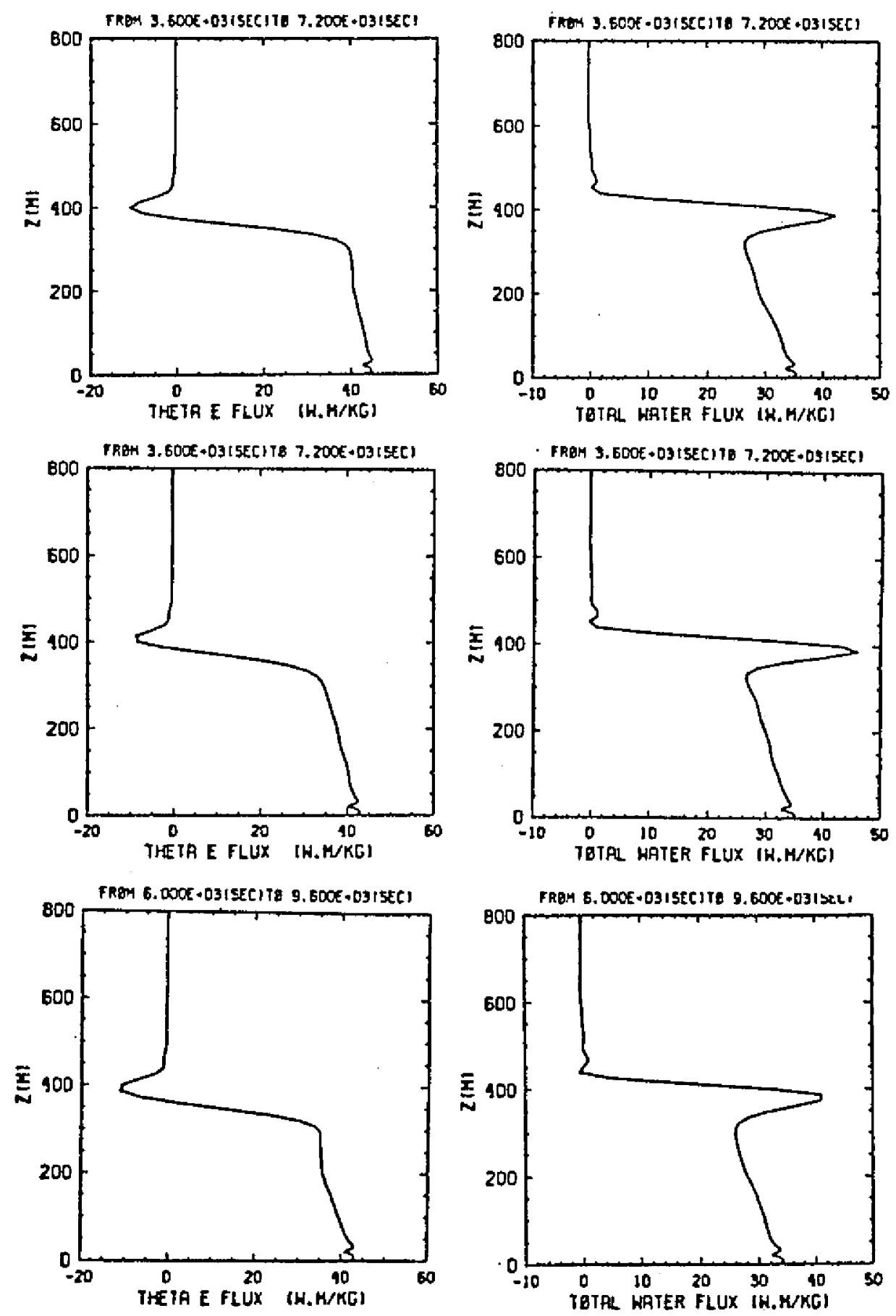

Fig. 7. (a) The $\theta_{e}$ and $r$ flux profiles computed in a period of the last one hour for experiments $A, B, C, D$ and $E$. The five rows are arranged in the order of experiments $A, B, C, D$ and $E$. 

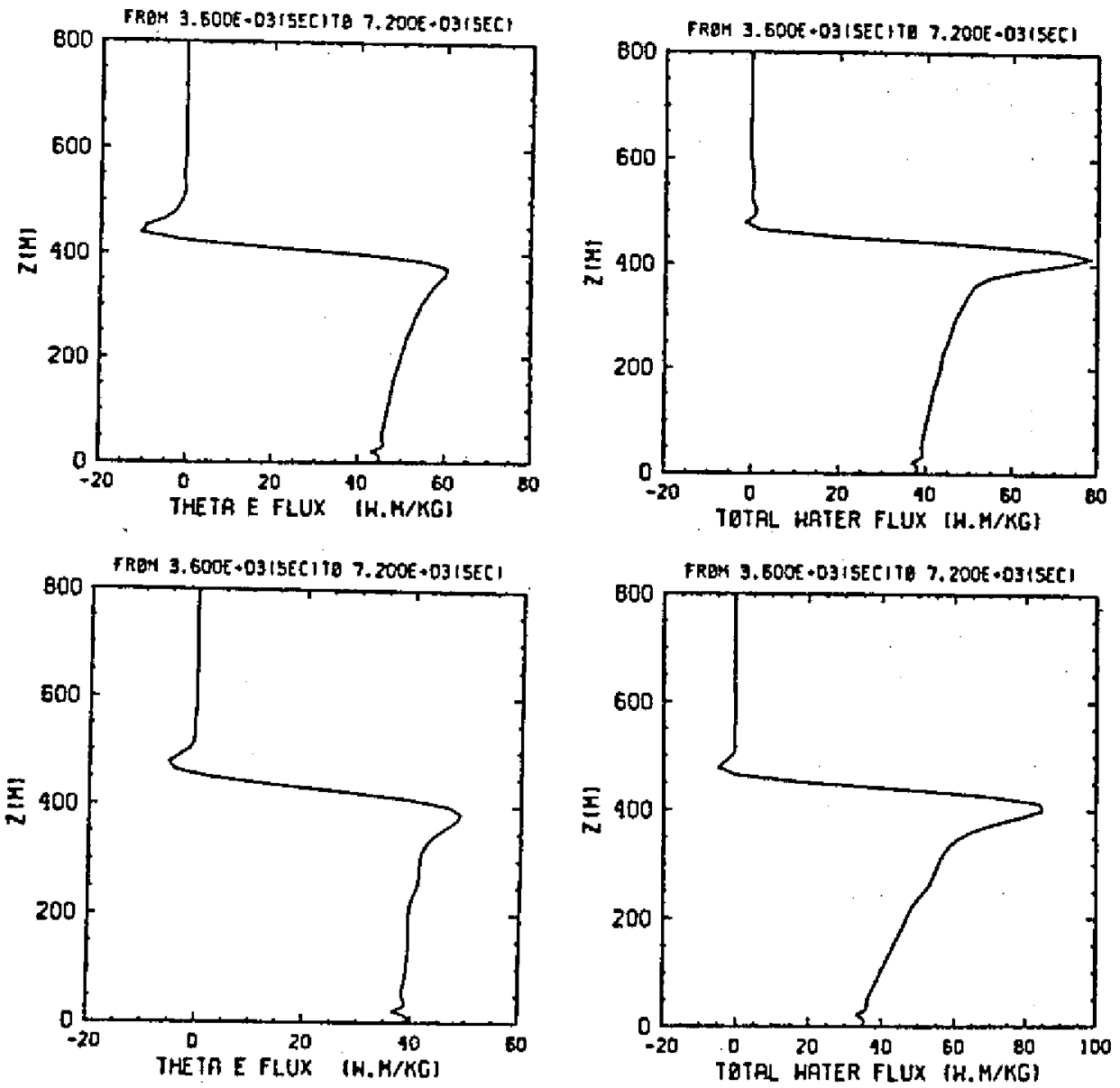

Fig. 7. (a) (Continued)
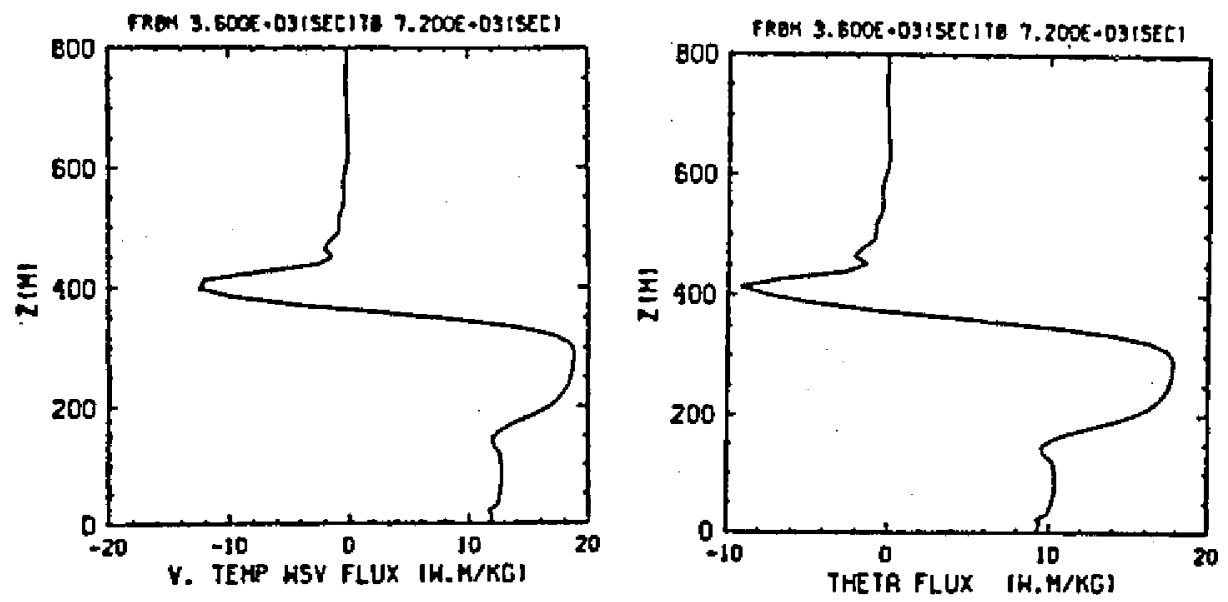

Fig. 7. (b) Same as Fig. 7a except for the flux profiles of $\theta$ and $\theta_{v}$. 

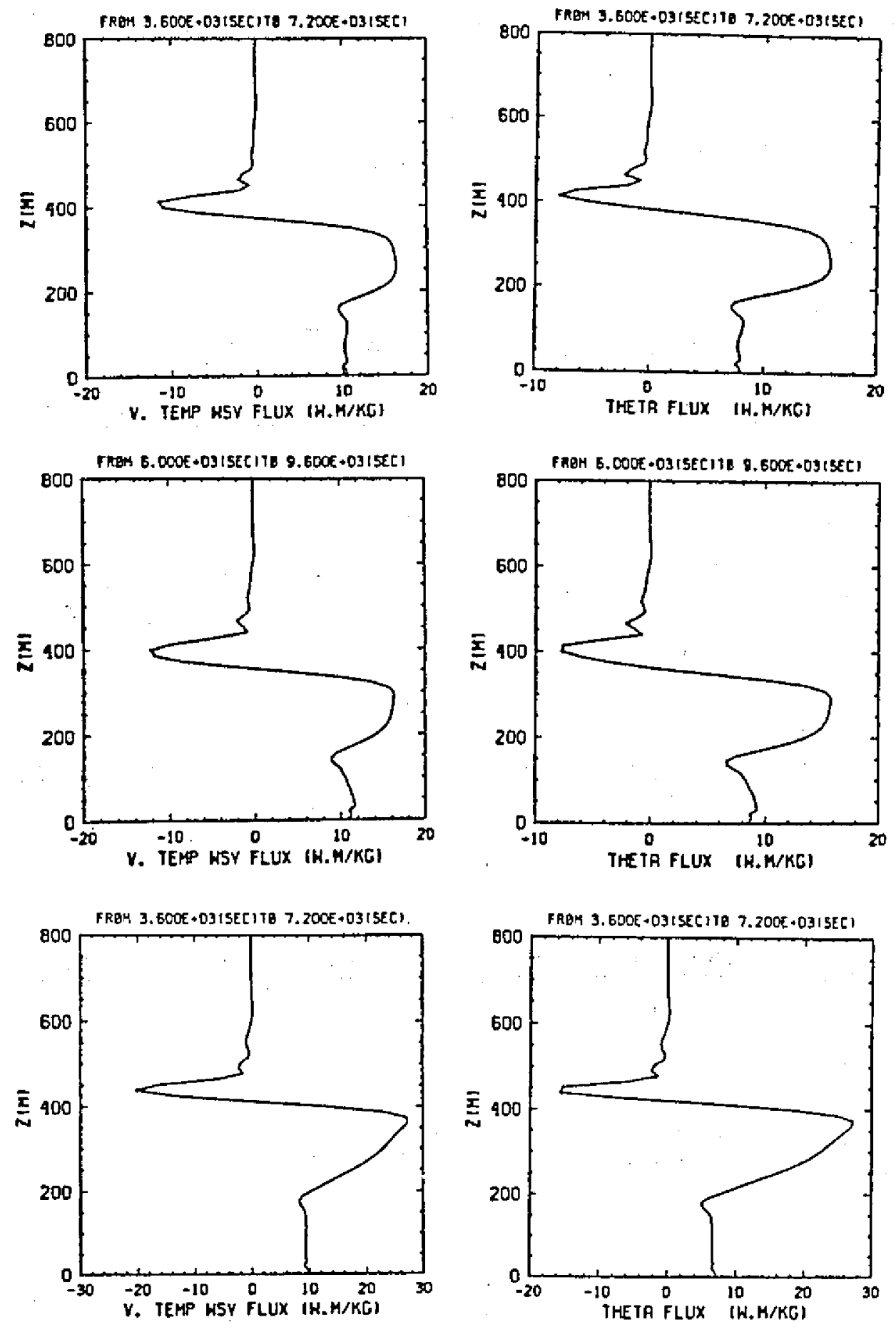

Fig. 7. (b) (Continued) 

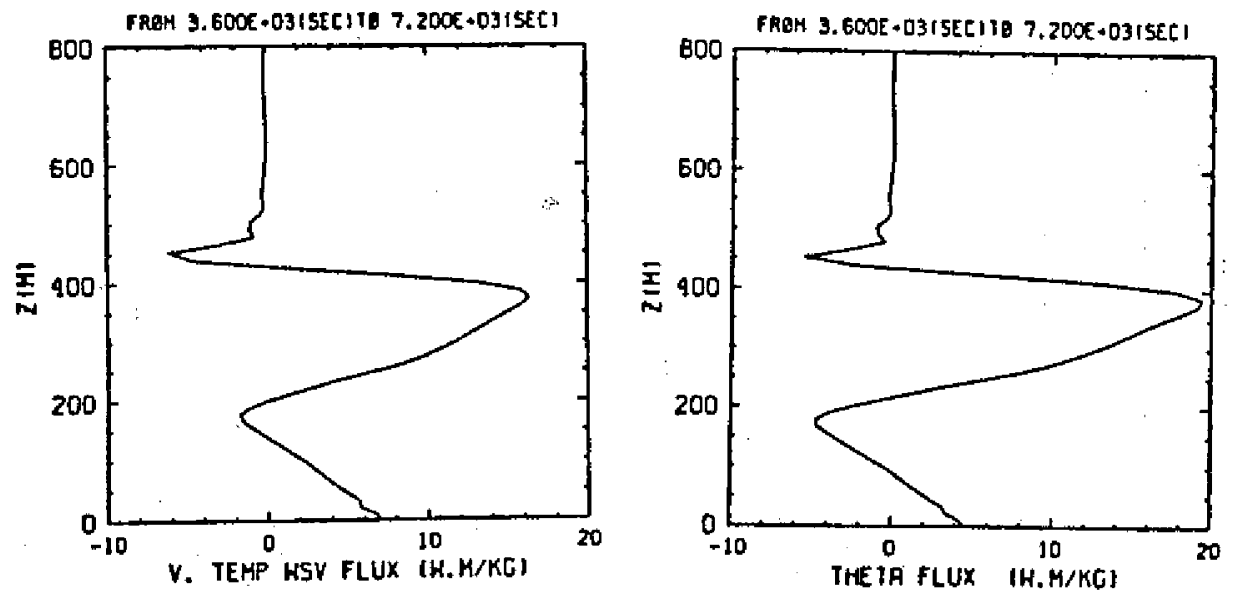

Fig. 7. (b) (Continued)
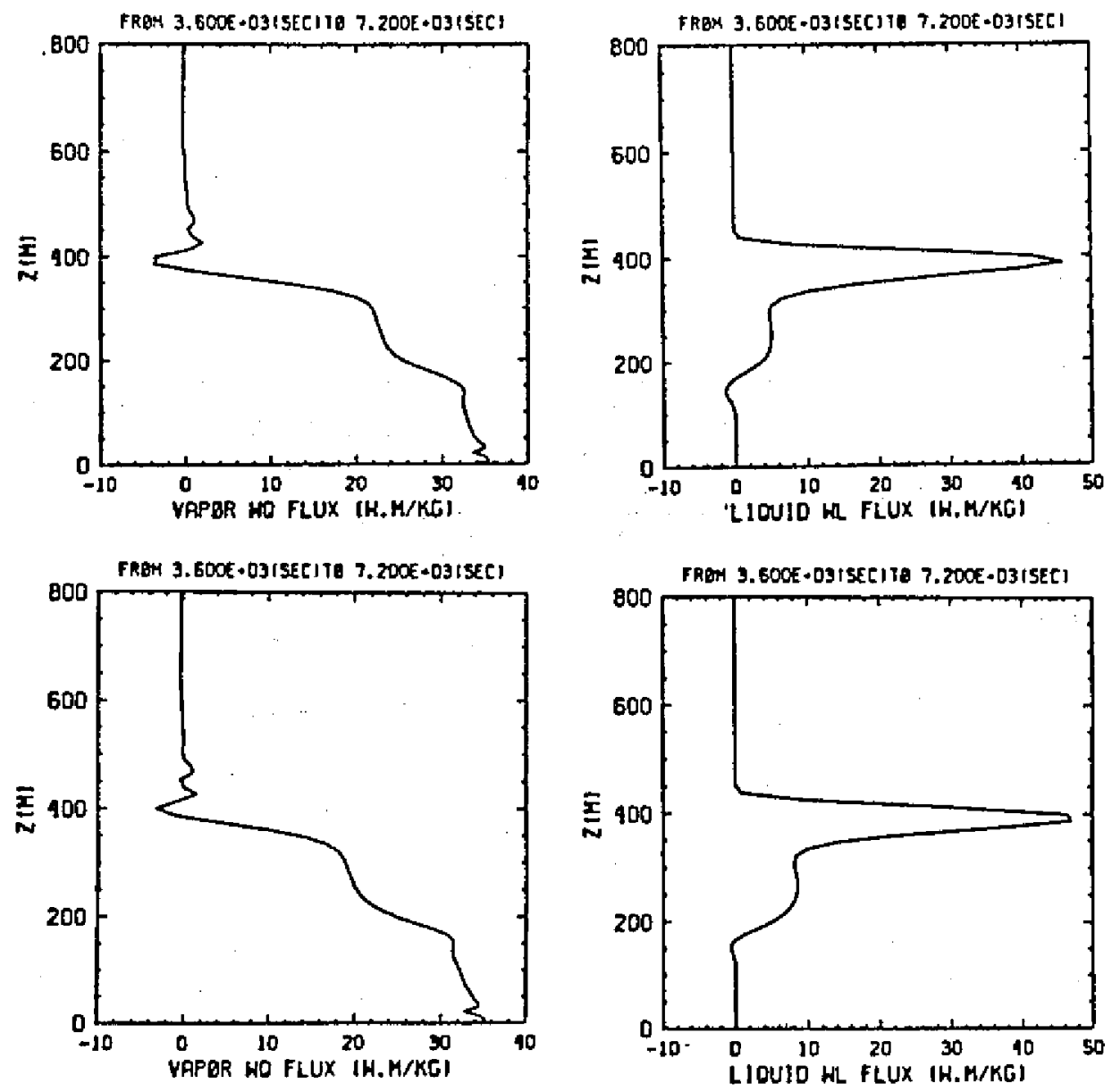

Fig. 7. (c) Same as Fig. 7a except for the flux profiles of $q$ and $l$. 

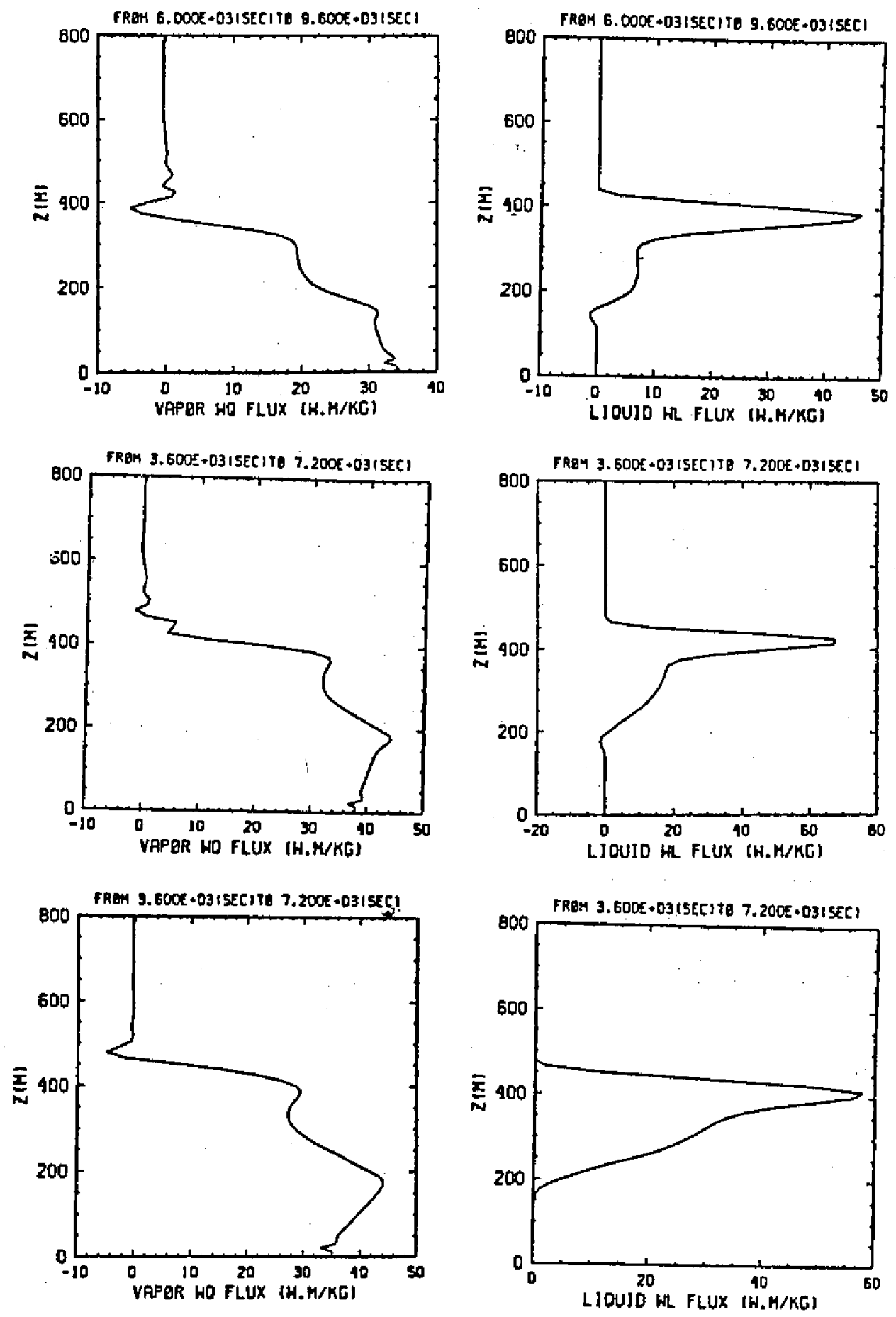

Fig. 7. (c) (Continued) 

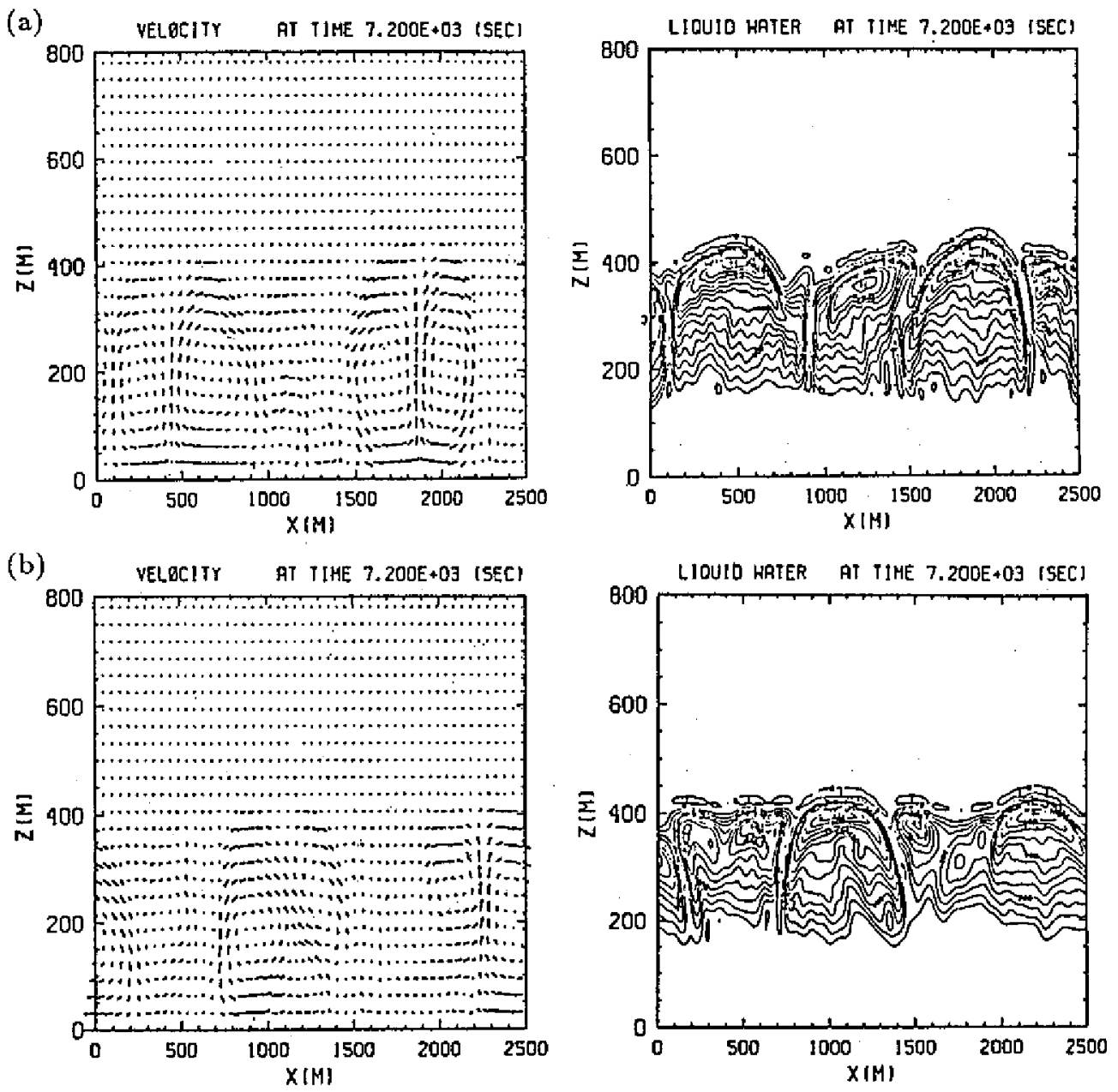

Fig. 8. The velocity and the liquid water mixing ratio fields in the physical domain for experiments $A, B, C, D$ and $E$. The velocity picture is presented in the left adjacent to the liquid water picture. The liquid water mixing ratio lines are labeled in $g \mathrm{~kg}^{-1}$ multiplied by 1000 . Arrows in velocity picture represent wind velocity scaled by maximum velocity. The experiments and the maximum velocity are as follows: (a) A, $2.80 \mathrm{~m} \mathrm{~s}^{-1}$; (b) B, $2.52 \mathrm{~m} \mathrm{~s}^{-1}$; (c) C, $2.93 \mathrm{~m} \mathrm{~s}^{-1}$; (d) $\mathrm{D}, 3.17 \mathrm{~m} \mathrm{~s}^{-1}$; (e) E, $1.57 \mathrm{~ms}^{-1}$.

From the results discussed above, there are two regimes of steady state behavior. One is from experiment $\mathrm{E}$ while others are from experiments $\mathrm{A}, \mathrm{B}, \mathrm{C}$ and $\mathrm{D}$. The radiative forcings used in experiments $\mathrm{A}, \mathrm{B}, \mathrm{C}$ and $\mathrm{D}$ are all inside the non-zero cloud fraction region while the forcing in experiment $\mathrm{E}$ is in the zero cloud fraction capping inversion. The infrared radiation sensitivity of the model is then only in the vertical placement relative to the cloud top. Once the radiative forcing is placed in the non-zero cloud fraction layer, the steady 

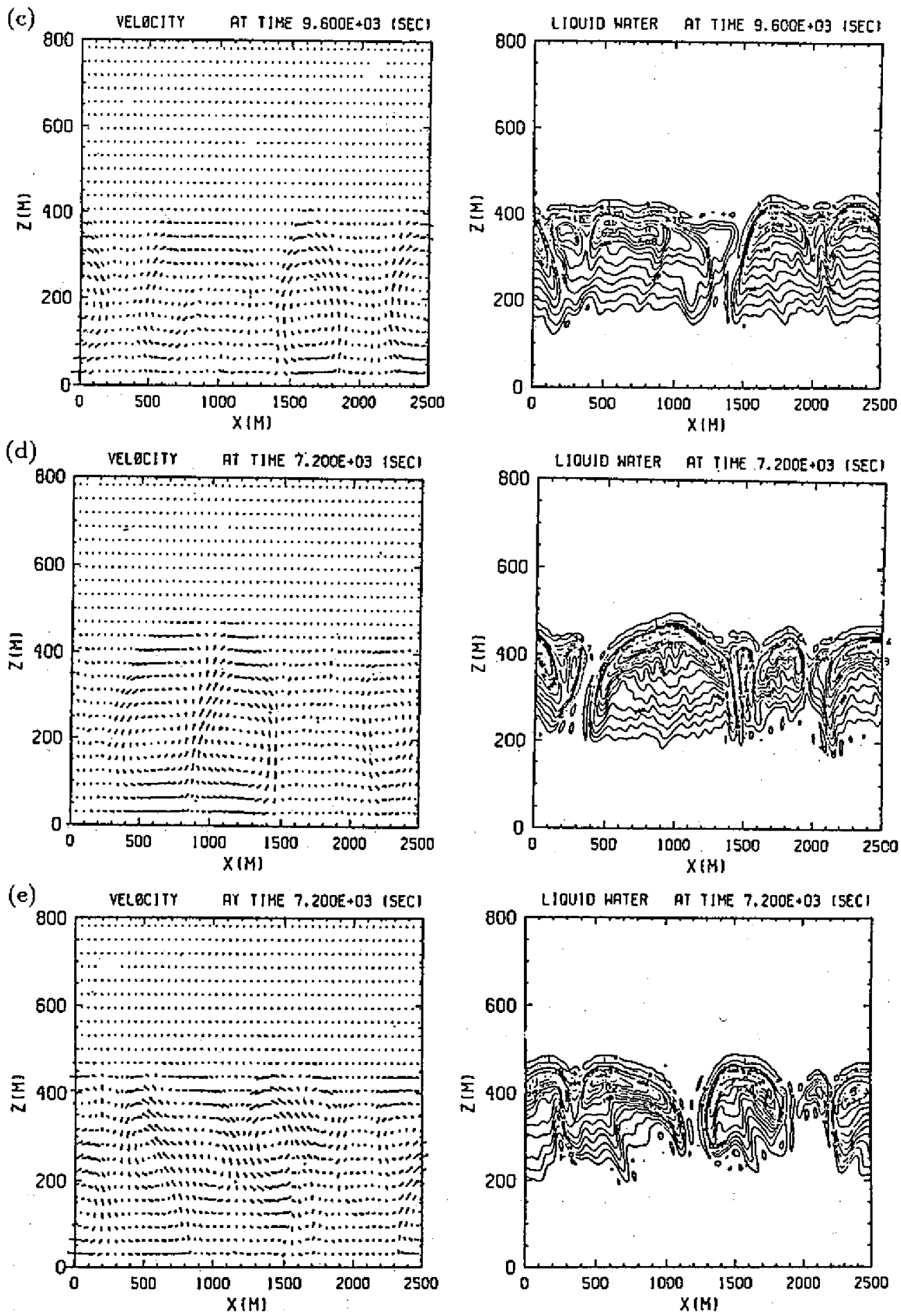

Fig. 8. (Continued) 
state of the model does not seem to be dependent on the horizontal or the vertical distribution of the cooling. This is probably due to the shorter time scale of the dynamical mixing (a few minutes as observed from the velocity field pictures). Before radiation can cool a local region appreciably to affect the dynamics, internal circulations must have already mixed away the parcels. As a result, the spatial variability in radiative cooling has no impact on the boundary layer equilibrium dynamics and the model's sensitivity appears to be in the vertical placement of radiative cooling relative to the turbulent cloud top region. Mixing line analysis to reinforce this time scale argument will be presented in the next section.

\section{MIXING LINE ANALYSIS}

To further study the impact of radiation on the dynamics, we employ the mixing line analysis. The liquid water potential temperature $\theta_{l}$ and total water $r$ (Betts, 1982) will be considered as conservative quantities for the mixing line analysis. If the diabatic process such as infrared radiative cooling has a slower time scale than the dynamical mixing, then the mixing will not be affected. As a result, conservative properties of the mixture will be linear combinations of the conservative properties of the original parcels (i.e. the inversion air parcel and the boundary layer air parcel); with the final properties depending on the fractional mixing of individual parcels involved. In terms of the mixing diagram using the conservative variables such as $\theta_{l}$ and $r$ as coordinates, this mixture will form a straight line with the slope of the straight line depending on the properties of the two original mixing parcels. On the other hand, no straight line will be found in a mixing diagram if radiation or some other diabatic processes affect the mixing process. Although this type of analysis cannot tell us explicitly the details of the mixing process, it can help us identify the impact of diabatic processes on the mixing. With this in mind we will see the mixing line analysis from the model. A typical observation from the DYCOMS

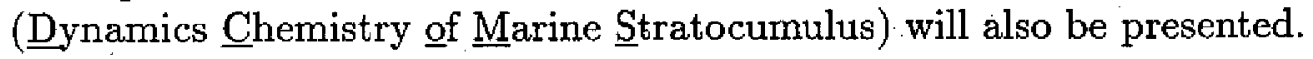

Mixing line analyses from the experiments A, B, C, D and E are shown in Fig. 9. In all cases, the $\theta_{l}$ and $r$ data were sampled from the height of 400 $m$ (50 $\mathrm{m}$ below the mean cloud top) to the height of $600 \mathrm{~m}$, at one time. It is obvious from Fig. 9 that the mixing line from experiments $\mathrm{A}, \mathrm{B}$ and $\mathrm{C}$ are straight and nearly identical. The mixing line from experiment $\mathrm{D}$ is straight but slightly spread. This is due to the fact that parts of the radiative cooling are applied to the cloud free area between the cloud cells. The mixing line from experiment $\mathrm{E}$ shows a totally different picture. The spread of data and the curve of the mixing line indicates a strong radiational impact on the dynamical mixing. The different mixing line as observed from experiment $\mathbf{E}$ is attributed 
(a)

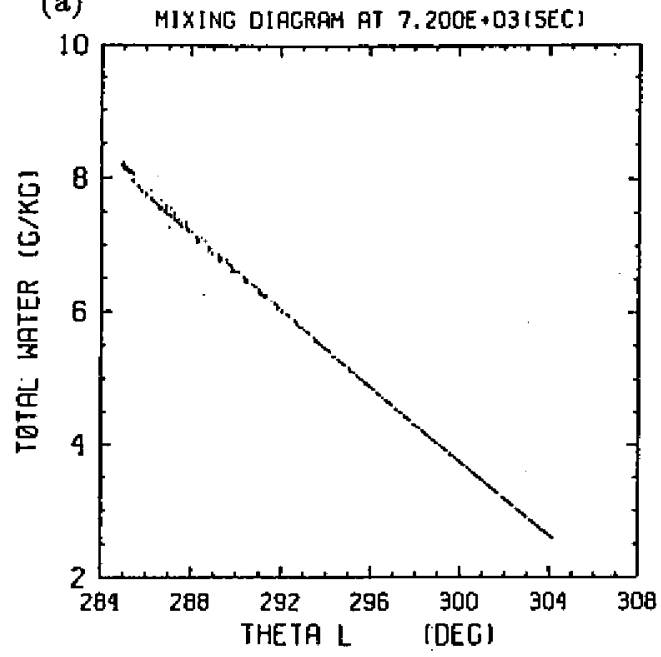

(c)

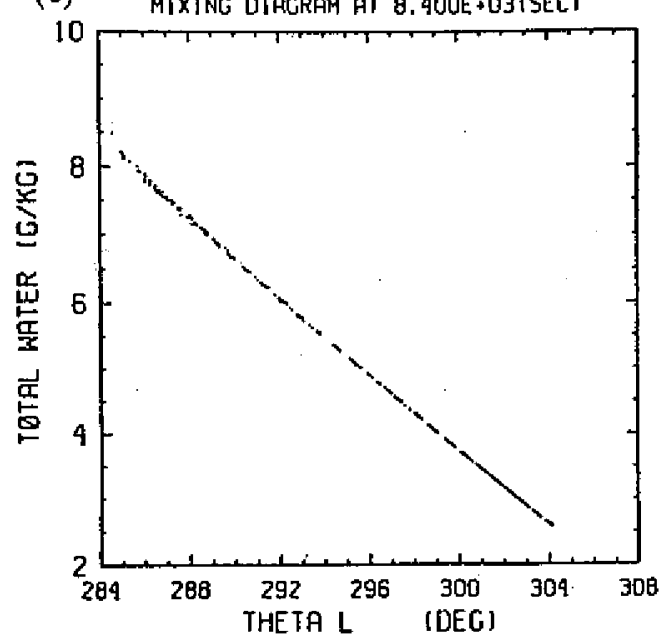

(b)

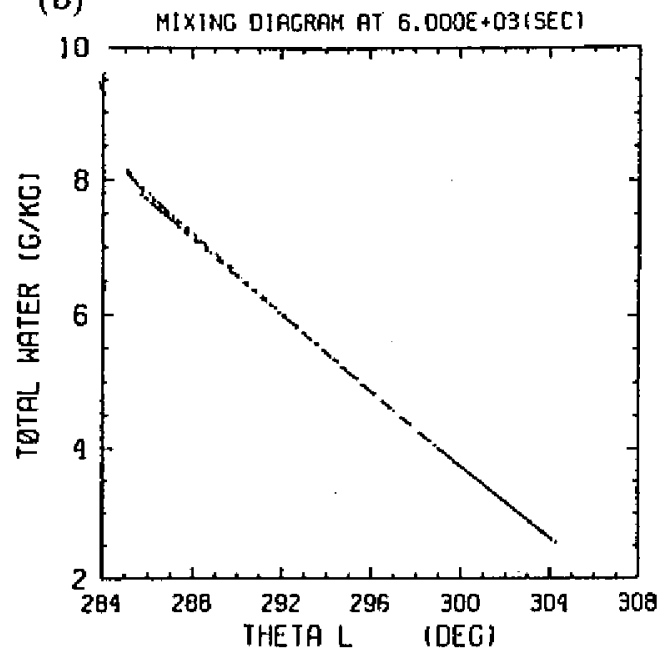

(d)

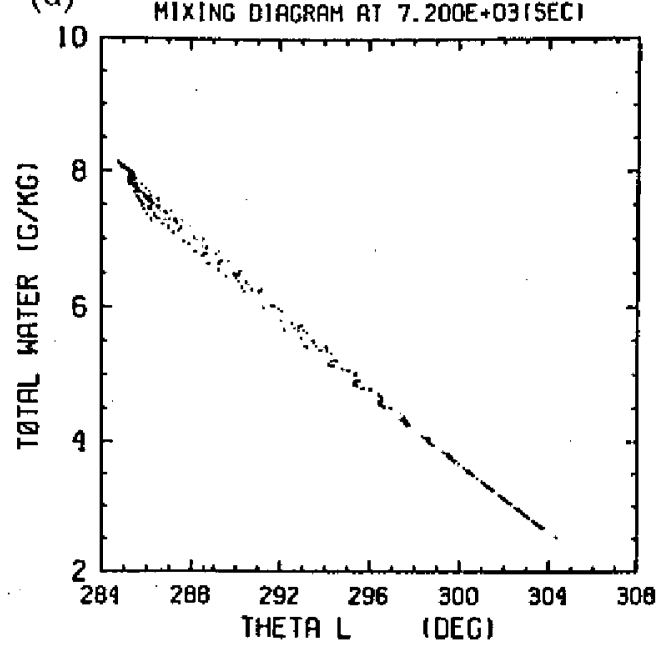

Fig. 9. The mixing line analysis from the experiments $A, B, C, D$ and $E$. The conservative variables used are liquid water potential temperature $\theta_{l}$ and total water mixing ratio $r$. The experiments and the time of the analysis are as follows: (a) A, 120 minutes; (b) B, 100 minutes; (c) C, 140 minutes; (d) D, 120 minutes; (e) E, 120 minutes.

to the lack of dynamical circulations or turbulence in the capping inversion. The weak turbulence makes the mixing time scale rather long so that radiation can build up and influence the dynamics. The straight mixing lines in experiments A, B, C and D explain why the different detail structure of radiation produced essentially the same boundary dynamics. They also suggest that the need to take the horizontal variability of radiation into account is really dependent on 


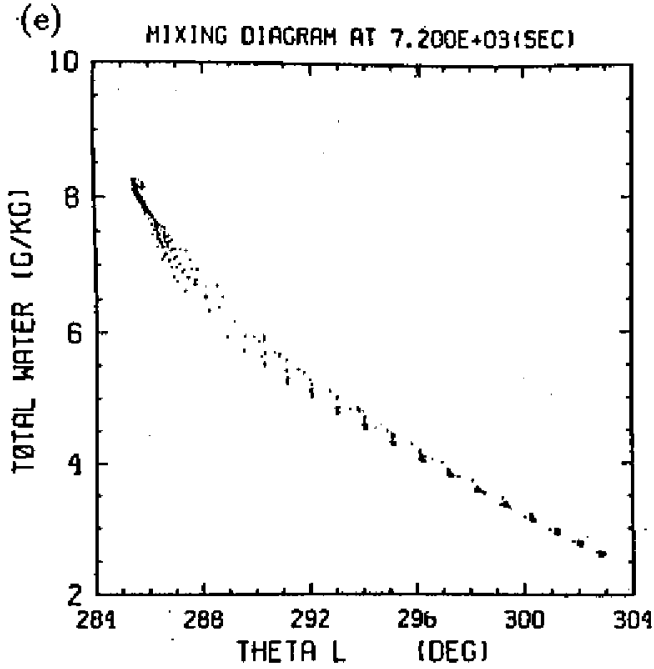

Fig. 9. (Continued)

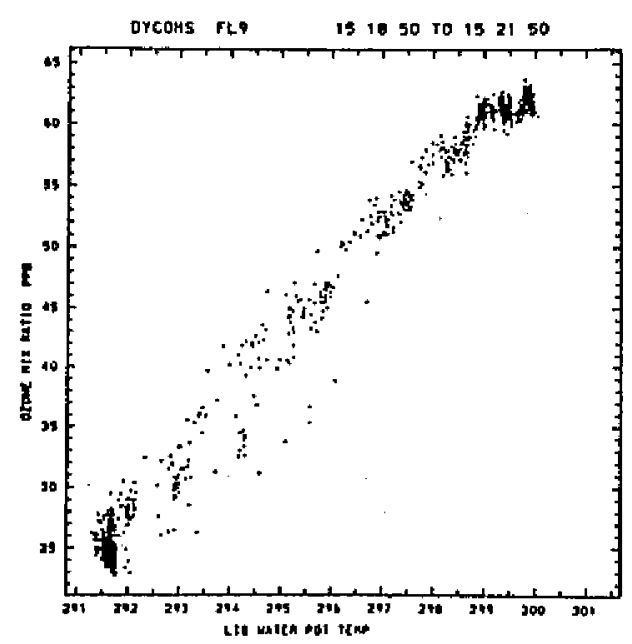

Fig. 10. A typical mixing diagram from the DYCOMS observation. The conservative variables used are liquid water potential temperature $\theta_{l}$ and $O_{3}$ mixing ratio (adopted from Weaver, 1987).

the comparison of the two time scales. Only when the dynamical circulations are weak and the time scale of dynamical mixing is comparable to the time scale of radiation build up do we need to be concerned about the detail structure of infrared radiation. Fig. 10 shows a typical mixing line from the DYCOMS observations (Adopted from Weaver; 1987). The conservative variables used are $\theta_{l}$ and a mixing ratio of $O_{3}$. The data are sampled by NCAR Electra from the cloud top region and the entrainment interface layer. Note that the inversion air has a higher concentration of $O_{3}$ and $\theta_{l}$. The nearly straight mixing line in Fig. 10 clearly indicates the time scales of radiation and $O_{3}$ photochemistry production/destruction are longer than the time scale of dynamical mixing; a fact consistent with the present model results when the model radiation is not unreasonably placed in the capping inversion.

\section{CONCLUDING REMARKS}

It is generally believed that the infrared cooling at the cloud top plays an important role in the maintenance of the cloud top inversion and the convective circulations in the cloud-topped bounary layer. Recent observations by tethered balloon and aircraft indicate that cloud top radiative cooling is likely to undergo significant horizontal as well as vertical variability. Stephens (1986) and Stephens and Platt (1987) emphasized the potential importance of a possible interaction between boundary dynamics and horizontally inhomogeneous 
radiation fields. In this paper, we have studied the interaction between the dynamics and infrared radiation in the cloud-topped marine boundary layer with a high resolution two-dimensional Fourier-Chebyshev spectral Boussinesq model. We have chosen to use the idealized radiative forcings rather than the onedimensional plane parallel radiative transfer calculations in the present stage of the work. The reasons are twofold. First, it is not clear that the plan parallel assumption is valid in a fine resolution model like ours. Stephens (1986) showed that the infrared cooling based on the more accurate three-dimensional radiative transfer calculation (which considers the inhomogeneity of the medium) in a Gaussian shaped cloud can differ significantly from the classical plane parallel solution. Also, we want to devote the majority of computer resources on the resolution necessary for simulation of non-radiative cloud-top processes. Secondly, as we have shown in our paper the dynamics of the boundary layer are insensitive to the different types of radiative cooling so long as most of the cooling is inside the turbulent boundary layer. Thus, the use of the simple radiative forcings seems to be justified. Obviously, our model results need to be substantiated by a high resolution three-dimensional dynamical model coupled with a radiative transfer calculation which is capable of handling the inhomogeneity of stratocumulus.

To investigate the impact of infrared cooling on the boundary layer dynamics, we have performed numerical simulations of the marine boundary layer convection with various spatial distributions of radiative cooling. These simulations include the effects of diabatic heating, turbulence and large scale mean conditions. The simulated stratocumulus cells in all cases appear to be domeshaped with sharp liquid water gradients on the sides. The simulated updraft is in the center of the convective cell while the downdraft is parallel to the side of the cell. The deformation fields associated with these upward and downward motions contribute to the sharp liquid water gradients across the cloud boundary; a fact also found in Klaassen and Clark's (1985) fine resolution simulation of cumulus clouds in the absence of ambient shear. Klaassen and Clark argued that the deformation fields near the cloud boundary are subject to nodal (baroclinic) instability. This nodal instability is closely related to the curnulus entrainment in their study. We suspect that the initiation of stratocumulus entrainment might be closely related to the cloud-top nodal instability under the situation of strong subsidence: The simulated downdraft regions do not always have higher cloud bases as predicted by the simple mixed layer model. This indicates that the downdraft may not always be undergoing much mixing with the inversion air. These updrafts and downdrafts form internal circulations which continually recycle air through the boundary layer and make the boundary layer well mixed. No vertically decoupled circulation between cloud and sub-cloud layers has been observed in the present study. Chai and Telford 
(1983) studied the stratocumulus cloud with a plume model. In their view, the stratocumulus-topped boundary layer is composed of a population of plumelike updrafts and downdrafts. These convective plumes continually circulate air through the boundary layer. The pictures emerging from our simulations are not too different from the plume concepts proposed by Chai and Telford. The simulated stratocumulus entrainment takes place in narrow descending plume-like elements that can extend through the depth of the cloud layer. The updrafts, however, appear to be broad, thermal-like features rather than the narrow plumes Chai and Telford envision.

The flux profiles from the experiments indicate that the dynamics and entrainment of the cloud-topped marine boundary layer do not depend on the detailed (horizontal and vertical) structure of infrared radiative cooling so long as the cooling is confined inside the turbulent boundary layer. This insen. sitivity of boundary dynamics to the different spatial distribution of infrared radiation is due to the much shorter time scale of the turbulence mixing. Any local instabilities induced by radiation are rapidly mixed out by the vigorous internal circulations inside the boundary layer. Although we have bypassed the estimations of radiation build up time scale and dynamical mixing time scale explicitly, mixing line analyses from both the model simulations and the DYCOMS observation confirm the time scale argument. As a result of this time scale difference, the sensitivity of the dynamics to the radiation is primarily related to the vertical positioning of the cooling relative to the inversion. Since the theory of radiation does not support any cooling occurring in the inversion, we need to consider the detailed structure of radiation only when the turbulent mixing time scale is comparable to the radiation build up time scale. Radiation effects are important, however, only in that they contribute to the overall destabilization and kinetic energy source of the boundary layer. Chai and Telford (1983) also used the argument of the small overturning time scale inside the cloud to exclude the radiative effect on their descending plumes. Their hypothesis on an individual plume is reinforced by our results.

While the observational mixing line supports our time scale argument, some questions remain to be answered. An immediate question concerns solar radiation as well as drizzle effects in the cloud-topped marine boundary layer. By properly including these two physical mechanisms in the model, interaction between dynamics and both infrared and solar radiation in a decoupled cloud and sub-cloud layers such as reported by Nicholls and Leighton (1986) can be studied. Another problem relates to the interaction of marine boundary dynamics and radiation on a larger horizontal scale. Finally, the implications for the simple mixed-layer modeling from dynamical modeling with numerical techniques and resolution sufficient to simulate the stratocumulus cloud-top process deserves further attention. 
Acknowledgements. The author would like to extend thanks to Scott Fulton for providing the package of Chebyshev routines which were so important for the completion of this research, to Clark Weaver for providing the 1985 NCAR Electra data, and to George Young, Wayne Schubert, Graeme Stephens, Terry Clark and Paul Ciesielski for helpful discussions.

This work was supported by NSF grant ATM-8510664 and ONR grant N00014-84-C-0591, with additional support from the Naval Oceanographic and Atmospheric Research Laboratory at Monterey and Cooperative Institute for Research in the Atmosphere (CIRA) at Colorado State University. Acknowledgment is also made to the National Center for Atmospheric Research, which is sponsored by the National Science Foundation, for computer time used in this research.

\section{REFERENCES}

Betts, A. K., 1982: Saturation point analysis of moist convective overturning. J. Atmos. Sci., 39, 1484-1505.

Chai, S. K., and J. W. Telford, 1983: Convection model for stratus cloud over a warm water surface. Bound. Layer Meteor., 25, 289-321.

Eliasen, E., B. Machenhauer, and E. Rasmussen, 1970: On a numerical method for integration of the hydrodynamical equations with a spectral representation of the horizontal fields. Report No. 2, Institut for Teoretisk Meteorologi, Kobenhavns Universitet, 35pp.

Fouquart, Y., 1985: WMO Workshop on Modeling of the Cloud-Topped Boundary layer. Fort Collins, Colorado.

Fulton S. R. and W. H. Schubert, 1987: Chebyshev spectral methods for limitedarea models. I: Model problem analysis. Mon. Wea. Rev., 116 (to appear).

Grassl, H., 1975: Albedo reduction and radiative heating of clouds by absorbing aerosol particles. Contrib. Atmos. Phys, 48, 199-210.

Klaassen, G. P., and T. L. Clark, 1985: Dynamics of the cloud-environment interface and entrainment in small cumuli: Two-dimensional simulations in the absence of ambient shear. J. Atmos. Sci, 42, 2621-2642.

Kuo, H. -C., 1983: Radiation fields in maritime stratocumulus. M. S. Thesis. Colorado State University.

Kuo, H. -C., 1987: Dynamical modeling of marine boundary layer convection. Ph.D. dissertation, Colorado State University. (Atmospheric Science Paper No. 412).

Kuo, H. -C., and W. H. Schubert, 1987: Stability of cloud-topped boundary layers. Quart. J. Roy. Meteor. Soc., 114, 887-916.

Kuo, H. -C., and T. H. Vonder Haar, 1986: Radiation effects on a Boussinesq 
boundary layer model. Preprints, 6th Conf. Atmos. Radiation, Amer. Meteor. Soc., Boston, 35-38.

Lilly, D. K., 1968: Models of cloud-topped mixed layers under a strong inversion. Quart. J. Roy. Meteor. Soc., 94, 292-309.

Moeng, C. -H., 1986: Large-eddy simulation of a stratus-topped boundary layer. Part I: Structure and budgets. J. Atmos. Sci., 43, 2886-2900.

Nicholls, S., and J. Leighton, 1986: An observational study of the structure of stratiform cloud sheets: Part I: Structure. Quart. J. Roy. Meteor. Soc, 112, 431-460.

Ogura, Y., and N. A. Phillips, 1962: Scale analysis of deep and shallow convection in the atmosphere. J. Atmos. Sci., 19, 173-179.

Orszag, S. A., 1970: Transform method for the calculation of vector-coupled sums: Application to the spectral form of the vorticity equation. J. Atmos. Sci., 27, 890-895.

Reynolds, D. W., T. H. Vonder Haar, and S. K. Cox, 1975: The effect of solar radiation absorption in the tropical troposphere. J. Appl. Met., 14, 433444.

Schubert, W. H., 1976: Experiments with Lilly's cloud-topped mixed layer model. J. Atmos. Sci., 33, 436-446.

Schubert, W. H., Wakefield, J. S., Steiner, E. J., and S. K. Cox, 1979: Marine stratocumulus convection. Part I: Governing equations and horizontally homogeneous solutions. J. Atmos. Sci., 36, 1286-1307.

Schubert, W. H., G. D. Taylor, S. R. Fulton and M. DeMaria, 1984: A Chebyshev spectral method for boundary layer models. Arch. Met. Geoph. Biocl., Ser. A33, 117-126.

Slingo, A., R. Brown and C. L. Wrench, 1982b: A field study of nocturnal stratocumulus. Part III. High resolution radiative and microphysical observations. Quart. J. Roy. Meteor. Soc., 108, 145-165.

Slingo, A., S. Nicholls and J. Schmetz, 1982a: Aircraft observations of marine stratocumulus during JASIN. Quart. J. Roy. Meteor. Soc., 108, 833-856.

Stephens, G., G. W. Paltridge and C. M. R. Platt, 1978: Radiation profiles in extended water clouds. Part III. Observations. J. Atmos. Sci., 35, 2133-2141.

Stephens, G., 1986: On radiative transfer through realistic atmospheres. Preprints, 6th Conf. Atmos. Radiation, Amer. Meteor. Soc., Boston, 224229.

Stephens, G., and M. R. Platt, 1987: Aircraft observations of the radiative and microphysical properties of stratocumulus and cumulus cloud fields. $J$. Climate. and Appl. Meteor., 26, 1243-1269.

Twomey, S., 1978: Comments on 'Effects of cloud size and cloud particles on satellite-observed reflected brightness'. J. Atmos. Sci., 308, 2389-2390. 
Weaver, C., 1987: Observational analysis of cumulus and stratocumulus entrainment using $\mathrm{O}_{3}$. Ph.D. Dissertation, Colorado State University.

Welch, R. M., S. K. Cox, and J. M. Davis., 1980: Solar radiation and clouds. Met. Mon. Amer. Met. Soc., 17, No. 39.

Wiscombe, W. J., R. M. Welch, and W. D. Hall., 1984: The effect of very large drops on cloud absorption. Part I: Parcel Models. J. Atmos. Sci., 41, $1336-1355$. 


\title{
輻射對於含層積雲邊界層的影響
}

\author{
郭鴻基 ${ }^{*}$ \\ 美國海軍海洋大氣砫究室
}

摘 要

觀測顯示層皘雲頂長波輻射冷卻區域的大小, 以及冷卻強度在水平及垂直力向有很大變 異性。我們用一個高效率, 高解析度的雲動力模式探討輻射場對雲動力及雲逸入的影響, 模 式結果顯示, 雲動力及雲逸入只對輻射冷卻相對於雲頂位置敏感。當輻射冷卻發生在雲中, 相對不同的水平及垂直冷卻分佈; 我們得到類似的雲內部環流及逸入。賞假設輻射發生在逆 溫層, 我們得到不一樣雲環流及逸入。模式結果可以輻射影響逸入的時間尺度以及混合時間 尺度解釋。

*目前地址：台灣大學大弹科學系，台灣 